\title{
Supporting teams to optimize function and independence in Veterans: a multi-study program and mixed methods protocol
}

\author{
Virginia Wang ${ }^{1,2,3^{*}}$ D, Kelli Allen ${ }^{1,4}$, Courtney H. Van Houtven ${ }^{1,2}$, Cynthia Coffman ${ }^{1,5}$, Nina Sperber ${ }^{1,2}$,
} Elizabeth P. Mahanna', Cathleen Colón-Emeric ${ }^{1,3,6}$, Helen Hoenig ${ }^{1,3,7}$, George L. Jackson 1,2,3 , Teresa M. Damush ${ }^{8,9,10}$, Erika Price $^{11,12}$ and Susan N. Hastings s, $^{1,6}$

\begin{abstract}
Background: Successful implementation of new clinical programs depends on effectively establishing, reorganizing, or enhancing team structures and processes to coordinate the work of individuals who are interdependent in their tasks, manage relationships, and share responsibility for outcomes. However, a one-size-fits-all approach is rarely effective. In partnership with VA national clinical leaders and local clinical champions, the Optimizing Function and Independence VA Quality Enhancement Research Initiative program (Function QUERI) will evaluate efforts to implement team-based clinical programs for Veterans at risk for functional decline and disability.

Methods: Function QUERI will implement and evaluate three innovative, evidence-based clinical programs in VA medical centers: (1) a group physical therapy program for knee osteoarthritis (Group PT); (2) assisted early mobility for hospitalized older veterans (STRIDE), a supervised walking program for hospitalized older veterans; and (3) implementation of helping invested family members improve veteran experiences study (iHI-FIVES), a skills training program for caregivers of disabled Veterans. A common reason for clinical care gaps in these populations is poor communication and coordination among the many interdisciplinary providers involved in their care. To facilitate the implementation of the clinical programs, Function QUERI will evaluate the impact of complexity science-based implementation intervention to promote team readiness (CONNECT), an implementation intervention designed as a bundle of interaction-oriented activities to promote team function and readiness for change, on the implementation of clinical programs across multiple sites. The evaluation will use a mixed methods design. Group PT is a local, single-site quality improvement project where a modified CONNECT intervention will be tested to inform the remaining program implementation projects. For STRIDE and iHI-FIVES projects, we will randomize participating sites to implement the clinical program, with the CONNECT intervention or not, and will use a stepped-wedge cluster randomized trial design.

Discussion: Function QUERI will translate its findings across its projects to identify the contextual factors and components from CONNECT that improve team processes and function to optimize effective implementation for future rollout of VA clinical programs. Synthesizing findings within and across projects, we will specify dimensions of team characteristics and function that enhance capacity for clinical innovation and uptake of evidence-based programs.

(Continued on next page)
\end{abstract}

\footnotetext{
* Correspondence: virginia.wang@va.gov

${ }^{1}$ Health Services Research and Development Center of Innovation, Durham

Veterans Affairs Health Care System, 508 Fulton St., Durham, NC 27705, USA

${ }^{2}$ Department of Population Health Sciences, Duke University School of

Medicine, Durham, NC, USA

Full list of author information is available at the end of the article
}

(c) The Author(s). 2018 Open Access This article is distributed under the terms of the Creative Commons Attribution 4.0 International License (http://creativecommons.org/licenses/by/4.0/), which permits unrestricted use, distribution, and

reproduction in any medium, provided you give appropriate credit to the original author(s) and the source, provide a link to the Creative Commons license, and indicate if changes were made. The Creative Commons Public Domain Dedication waiver (http://creativecommons.org/publicdomain/zero/1.0/) applies to the data made available in this article, unless otherwise stated. 
(Continued from previous page)

Trial registration: NCT03300336 Registered September 28, 2017, NCT03474380 Registered March 15, 2018.

Keywords: Implementation, Function, Veterans, VA, Healthcare team

\section{Background}

Clinical improvement efforts require team structure that coordinates the work of individuals who are interdependent in their tasks, manage relationships within one or more social systems (e.g., service line, facility), and share responsibility for outcomes. Teams influence relationship patterns that emerge within workgroups [1], which have a significant impact on individual and collective attitudes, behaviors, and performance $[2,3]$. While most organizational change and quality improvement (QI) efforts focus on changing individual behavior, less attention has been paid to improving the work and processes of teams. Effective management strategies that focus on fostering productive interdependencies among individuals engaged in change efforts may lead to better outcomes than strategies focusing on individuals alone $[4,5]$.

Team factors are especially important in interdisciplinary care settings where expertise and skills vary among clinicians involved in patient care. Moreover, there is limited evidence elucidating the features of teams (i.e., size, communication, role clarity) that are associated with clinical performance and successful implementation of non-acute services in hospital and specialty care settings. Consistent with an emerging literature indicating that team process and effectiveness are associated with improvements in patient-centered care [6], the Optimizing Function and Independence VA Quality Enhancement Research Initiative (QUERI) program (hereafter Function QUERI) will evaluate the impact of teams on the implementation and effectiveness of new clinical programs in specialized and acute care settings for patients at risk for impairment of function and independence. In addition, Function QUERI will test an intervention designed to improve team function and readiness for change, as a strategy for promoting effective implementation of Function QUERI's clinical programs.

To accomplish Function QUERI's overall goals, we will:

1. Implement and evaluate three new clinical programs, Group PT for knee osteoarthritis, STRIDE, and iHI-FIVES, that fill gaps in current clinical care for Veterans at risk for functional decline and disability

2. Adapt a novel complexity science-based implementation intervention to promote team readiness $(C O N N E C T)$ for use in a diverse mix of clinical settings and Veterans Affairs Medical Centers (VAMCs)
3. Examine the impact of CONNECT and team processes on implementation within and across projects.

\section{Methods}

\section{Overview of the three program projects}

The Function QUERI program will implement and evaluate three innovative, evidence-based clinical programs that fill gaps in current clinical care for Veterans at risk for functional decline and disability and will be conducted in VA medical centers throughout the national VA Health Care System. Guided by the International Classification of Functioning, Disability and Health [7], Function QUERI's clinical programs directly address known stressors and contextual factors that influence functional ability and independence. The three clinical programs will be implemented as QI projects, and the evaluation will be conducted as human subjects research approved by the Durham VA Health Care System Institutional Review Board.

The first of the three Function QUERI projects evaluates the implementation and features of Group PT, a group-based physical therapy program to improve access to therapy for Veterans with knee osteoarthritis (OA). With a lifetime risk of $45 \%$ and rising overall prevalence $[8,9]$, knee OA is one of the most common chronic health conditions and a leading cause of pain and disability among adults [10-16]. Despite evidence that PT improves knee OA pain, disability, and other key outcomes [17-22], PT is underutilized [23]. Group PT is designed to enhance efficiency of care by providing more contact hours of care per patient with fewer total clinician hours, compared to traditional individual PT. The program involves six 1-h, weekly, group-based sessions comprising up to 10 patient participants. At patients' first session, a physical therapist conducts a brief evaluation and administers baseline functional tests and questionnaires; functional tests and questionnaires are repeated at the last session. At each session, the physical therapist leads the group in strengthening and stretching exercises, as well as brief education and discussion modules. Patients are instructed to perform assigned exercises at home. Results from a trial demonstrated similar outcomes between Group PT and traditional individual PT for knee OA, but the Group PT program has a lower cost [24]. Group PT is a 1-year project that takes place in a single site to evaluate key outcomes of sustainability and ways to improve the reach of the program for wider dissemination. It also serves as a case study for the 
CONNECT implementation intervention, the experiences of which will inform refinements to CONNECT trainings and content for application in other Function QUERI projects.

Project 2 evaluates the implementation of assisted early mobility for hospitalized older veterans (STRIDE), a supervised walking program for hospitalized older Veterans focused on maintaining musculoskeletal strength and mobility during hospitalization, a highly vulnerable time for development of disability. A key contributor to hospitalassociated disability is immobility during hospitalization [25]. While fewer than $5 \%$ of patients have physician orders for bed rest, hospitalized older adults spend only $4 \%$ of their time standing or walking [26]. The hazards of immobility in the hospital have been recognized for more than 2 decades [27]. Previously developed hospital mobility interventions have demonstrated the potential of inpatient walking to prevent declines in mobility during hospital stays and to reduce hospital lengths of stay [28-34], but there are currently no VA system-wide approaches to address this important gap in clinical care. Adapted from a mobility program tested in three non-VA hospitals that led to reduced hospital lengths of stay [35], STRIDE is designed for patients aged $>60$ and consists of a one-time gait and balance assessment conducted by a physical therapist, followed by daily supervised walks by a recreation therapy assistant for the duration of the hospital stay [36]. Clinical demonstration of STRIDE conducted at the Durham VA Health Care System (VAHCS) resulted in a greater likelihood of discharge to home (than to skilled nursing or rehabilitation) among STRIDE participants compared to clinically similar patients receiving usual care (92 vs $74 \%, p=0.007$ ) [36]. Based on the cumulative evidence on early mobility, positive staff, and patient assessments of STRIDE, it was established as a permanent clinical service at the Durham VAHCS and has the potential to become a system-wide approach to address hospital-associated disability in the VHA. Function QUERI's STRIDE implementation is a multi-year project that will be implemented across eight participating VAMCs.

Project 3 examines the implementation of helping invested family members improve veterans experiences study (iHI-FIVES) to promote function and independence through skills training and support for caregivers of Veterans with cognitive and/or functional limitations. The Veterans Health Administration (VHA) has the most extensive system of home and community-based services of any health care system in the USA and yet about two-thirds of the 5.5 million Veterans who receive care in the home receive it exclusively from family and friends. Caregivers allow Veterans to avoid or delay nursing home entry [37], but caregiving can result in high rates of caregiver burden, depression, cost, and health risk to Veterans themselves. Caregivers commonly report unmet needs for caregiver skills training [38], which can reduce negative consequences of caregiving, increase quality of care, and optimize patient independence [39-44]. HIFIVES is a multi-modal training program that occurs after a Veteran's referral to home and community-based services. Its training sessions address standardized and caregiver-selected topics such as increasing Veteran function and independence, caregiver injury prevention and self-care, communicating with providers, and navigating the VHA [45]. Caregivers are encouraged to create action items to apply the skills learned, including incorporating the use of relaxation techniques into their busy lives. Results from the HI-FIVES trial (NCT01777490) found that HI-FIVES significantly increased Veteran and caregiver's experience of VA care. The trial yielded limited effects on increasing patient days at home, which may be explained by the trial's limitation of being underpowered to detect statistically significant differences (due to larger than expected variance). Thus, a larger sample size is needed to detect true differences in days at home, the primary outcome. Based on the results to date, the VA National Program Office on Caregiver Support is promoting HI-FIVES for wide-scale dissemination. Function QUERI will capitalize on this effort and support the implementation of HI-FIVES (iHI-FIVES) project by facilitating the rollout of caregiver trainings across eight participating VAMC sites and evaluating the program, with its increased enrollment for definitive retesting on a larger sample $(n \geq 400)$ in this hybrid type III effectiveness-implementation design. Caregiver Support Program staff and Geriatrics and Extended Care Services staff will be recruited to offer iHI-FIVES.

As described in Table 1, Function QUERI's three clinical programs promote a shared goal of optimizing physical function and independence among Veterans while potentially delaying the onset of costly disability. An important challenge and consideration is understanding optimal methods to disseminate these promising programs more widely and in a sustained way. Our initial program experience suggests that inter-professional relationships and team dynamics are the key determinants to the success of new hospital-based clinical programs that require collaborative processes involving multiple disciplines. Indeed, a major reason for clinical care gaps in this population is poor communication and coordination among the many interdisciplinary providers involved in their care. Implementing new programs in diverse settings requires buy-in and cooperation among many different service lines, and a one-size-fits-all approach is rarely effective.

\section{Implementation core}

Providing expertise in implementation science, organizational behavior, and quantitative and qualitative analyses, 
Table 1 Overview of optimizing function and independence QUERI (Function QUERI) projects

\begin{tabular}{|c|c|c|c|}
\hline \multirow[t]{2}{*}{ Overview of projects } & Group PT & STRIDE & iHI-FIVES \\
\hline & Outpatient physical therapy & Inpatient walking assistance & Caregiver (CG) skills training \\
\hline \multicolumn{4}{|l|}{ Context of clinical program } \\
\hline Relevant clinical service & $\begin{array}{l}\text { Physical medicine and } \\
\text { rehabilitation (PM\&R) }\end{array}$ & Inpatient general medicine & $\begin{array}{l}\text { Caregiver (CG) support program or other } \\
\text { service lines that support CGs }\end{array}$ \\
\hline Nature of clinical program tasks & $\begin{array}{l}\text { Existing task, alternative } \\
\text { mode of delivery }\end{array}$ & New task & Existing task, alternative mode of delivery \\
\hline Team formation & Existing team (processes) & $\begin{array}{l}\text { Existing team (formation) New } \\
\text { team (processes) }\end{array}$ & $\begin{array}{l}\text { New team (formation) Existing team } \\
\text { (processes) }\end{array}$ \\
\hline $\begin{array}{l}\text { Program delivery: boundary } \\
\text { spanning? }\end{array}$ & No & $\begin{array}{l}\text { Yes: general medicine, nursing, } \\
\text { physical therapy }\end{array}$ & $\begin{array}{l}\text { Both (across service lines, within CSP } \\
\text { or GRECC) }\end{array}$ \\
\hline $\begin{array}{l}\text { Team membership: roles in } \\
\text { program delivery }\end{array}$ & $\begin{array}{l}\text { - Physicians: referral } \\
\text { - Physical Therapist: initial } \\
\text { evaluation, lead sessions } \\
\text { - Physical Therapy Assistant: } \\
\text { co-lead sessions }\end{array}$ & $\begin{array}{l}\text { - Physicians: referral } \\
\text { - Registered nurse: coordination, } \\
\text { assessment } \\
\text { - Physical therapist: assessment, } \\
\text { walking, supervise walks } \\
\text { - Nurse assistant, physical } \\
\text { therapy assistant, volunteer: } \\
\text { supervise walks }\end{array}$ & $\begin{array}{l}\text { - Physicians: referral } \\
\text { - Social worker: referral and training } \\
\text { - CG support coordinator: training } \\
\text { - Registered nurse: training } \\
\text { - Psychologist: training }\end{array}$ \\
\hline $\begin{array}{l}\text { Noted challenges in program } \\
\text { delivery to be addressed by } \\
\text { CONNECT }\end{array}$ & $\begin{array}{l}\text { - Awareness of Group PT } \\
\text { outside PM\&R } \\
\text { - Clarity of roles } \\
\text { - Established procedures } \\
\text { - Interaction within the } \\
\text { PM\&R service }\end{array}$ & $\begin{array}{l}\text { - Clarity of roles } \\
\text { - Availability of staff resources } \\
\text { - Communicating relevant clinical } \\
\text { information and "prescribed dose" } \\
\text { of STRIDE }\end{array}$ & $\begin{array}{l}\text { - Awareness of the CSP and its mission } \\
\text { in clinical units } \\
\text { - Clarity of roles, fragmented/duplicative } \\
\text { services for CG support across service } \\
\text { lines, enhance continuity of caregiver } \\
\text { support }\end{array}$ \\
\hline \multicolumn{4}{|l|}{ Outcomes of interest } \\
\hline Implementation outcomes & $\begin{array}{l}\checkmark \text { Penetration } \\
\checkmark \text { Fidelity } \\
\checkmark \text { Provider experience }\end{array}$ & $\begin{array}{l}\checkmark \text { Penetration } \\
\checkmark \text { Fidelity } \\
\checkmark \text { Team processes } \\
\checkmark \text { Provider experience }\end{array}$ & $\begin{array}{l}\checkmark \text { Penetration } \\
\checkmark \text { Fidelity } \\
\checkmark \text { Team processes } \\
\checkmark \text { Provider experience }\end{array}$ \\
\hline Patient/service-level outcomes & $\begin{array}{l}\checkmark \text { Function } \\
\checkmark \text { Pain } \\
\checkmark \text { Wait times } \\
\checkmark \text { Patient satisfaction } \\
\checkmark \text { Provider satisfaction } \\
\checkmark \text { Budget impact }\end{array}$ & $\begin{array}{l}\checkmark \text { Discharge to SNF } \\
\checkmark \text { Physical function } \\
\checkmark \text { Community mobility } \\
\checkmark \text { HRQoL, sleep, depression } \\
\checkmark \text { Hospital LOS } \\
\checkmark \text { Patient satisfaction } \\
\checkmark \text { Budget impact }\end{array}$ & $\begin{array}{l}\checkmark \text { Days in community } \\
\checkmark \text { CG Depressive symptoms } \\
\checkmark \text { CG Burden } \\
\checkmark \text { CG Satisfaction with VA care received } \\
\checkmark \text { Budget impact }\end{array}$ \\
\hline
\end{tabular}

our implementation core serves as an essential bridge across all Function QUERI projects. The implementation facilitation component of the core will develop and facilitate the implementation activities for Group PT, STRIDE, and iHI-FIVES with participating sites. The data and analytic component of the core will develop survey and interview instruments, establish common measurement of team characteristics and outcomes across projects (when possible), and evaluate the impact of teams on implementation and programmatic outcomes. Organizing the projects through this implementation core provides economies of scale and minimizes variation in processes and effort across projects and the participating sites. Implementation core activities are described in more detail below.

\section{Guiding framework for implementation and evaluation} Our program of work is informed by Grol and Wensing's Implementation of Change Model (IoC) [46] and the Consolidated Framework for Implementation
Research (CFIR) [46, 47] which, in combination, provide a comprehensive approach to implementing new clinical programs, from development through execution, evaluation, and dissemination. Specifically, the $\mathrm{IoC}$ model describes a process of implementation, beginning with the identification of practices (i.e., clinical programs) to address gaps in care for patients with (or at-risk for) impaired function and independence, defining targets for improvement, developing and executing implementation strategies, and continuous evaluation and adaptation of implementation to improve processes and outcomes. IoC is consistent with tenets of complexity science, acknowledging that implementation processes in complex systems require flexible and iterative approaches and constant monitoring and assessment [46, 48]; IoC is thus an appropriate framework to guide the development and execution of Function QUERI's implementation strategies (described in more detail below). Evaluation and dissemination approaches are informed by the CFIR, 
which is a macro-level model of implementation that describes a comprehensive taxonomy of operationally defined domains influencing implementation. Each CFIR domain is informed by an array of theoretical constructs from various disciplines. We adapted CFIR to inform our evaluation of team-based implementation strategies for Function QUERI's complex clinical programs.

We use our program's nested model of team function and performance (Fig. 1) to guide our evaluation of implementation, which draws from complexity science $[4,48]$, organizational theories on change and team behaviors, and the CFIR. Our model posits that the successful implementation of clinical programs is a function of team structure, team processes (i.e., CFIR's inner setting), the environmental context (i.e., outer setting), and the prescribed work characteristics of our innovative clinical programs. Altogether, these factors affect providers' engagement, interactions, and work activities, which collectively affect the ability of teams to accomplish their goals. Understanding the relationships among clinical program characteristics, team processes, team characteristics, and environmental contexts is critical to implementing and evaluating programs for Veterans at risk for functional decline and loss of independence.

\section{Implementation strategies: activities and intervention Overview}

Based on preliminary assessment of barriers to program implementation for each project (noted in Table 1) and input from our clinical and operational VA partners, Function QUERI will use Replicating Effective Programs (REP) as the overarching implementation framework for incorporating new clinical programs into routine practice [49]. REP has many advantages for implementation; for Function QUERI, REP is ideal because it provides a structure for specifying core elements of a program to be disseminated and for operationalizing elements that can be adapted to local settings. However, there are limitations to its use as well. In particular, an often noted barrier to implementation of new clinical programs is a focus on the clinical program content while ignoring the organizational learning context and processes needed to successfully implement change [50]. Function QUERI addresses this challenge by testing an implementation strategy designed to improve team function and readiness for change, which we posit as a pre-condition of effective implementation of clinical programs involving interdisciplinary care teams. In concert with program implementation, the implementation core will pair REP, the implementation framework, with an innovative

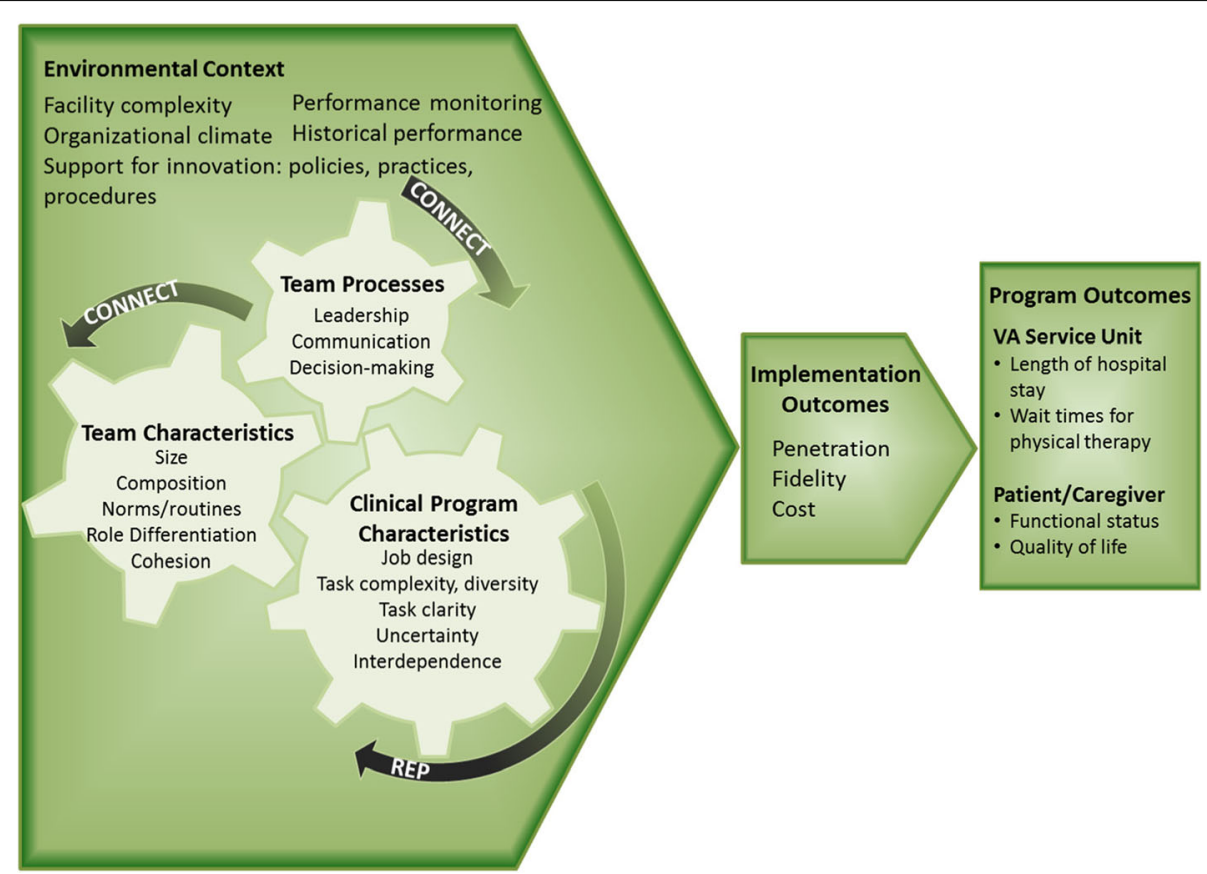

Fig. 1 Nested model of team function and performance in implementation. Notes: (1) Team characteristics and processes, their environmental context, and the prescribed work characteristics of Function QUERI's clinical programs both affect and are affected by one another in a nonlinear fashion. Collectively, these factors are critical to successful implementation of new clinical programs and improvements in patient care. (2) Replicating Effective Programs (REP) is a framework of processes for implementing new clinical programs into VA practice. Function QUERI REP processes, by project, are described in Additional file 1. (3) CONNECT is a novel implementation intervention to facilitate and enhance team function and readiness to implement Function QUERI's new clinical programs 
implementation intervention-CONNECT - to facilitate the readiness of teams to adopt new clinical programs $[50,51]$.

\section{Replicating Effective Programs}

Replicating Effective Programs (REP) is a package of strategies, originally developed to support dissemination of behavioral and treatment interventions for HIV in community settings [52]. REP has been described both as a framework for implementation processes [49] and as a strategy that has been effective in implementing new practices $[53,54]$. Function QUERI uses REP as a framework, or guide for implementation, which comprises an integrated bundle or package of discrete, standardized activities that address common barriers to implementation success [54, 55]. REP is designed for rollout of new programs through four phases of activity: precondition, pre-implementation, implementation, and maintenance. Across these phases, REP is delivered through a combination of standardized activities (Additional file 1). Each Function QUERI project has already initiated the REP pre-condition phase, by identifying needs and gaps in clinical care and the clinical programs that will be used to fill these gaps. Preimplementation phase activities will include drafting clinical program implementation packages, with input from stakeholders from VA operations. Packages include standardized program materials for clinical staff to implement the program (e.g., training manuals, procedures, competencies) and guidance on core elements of the program and options for customization. Throughout the implementation and maintenance phases, Function QUERI will also provide technical assistance and support to participating sites. The final step in REP is refining clinical program implementation packages in preparation for wider-scale dissemination.

\section{CONNECT}

Informed by social constructivist and learning theories and complexity science, which describe learning as a social process drawn from engaged interactions and information flow, CONNECT is a bundle of interactionoriented activities designed to supplement implementation efforts by promoting team function and readiness for change [50, 56-61]. CONNECT was originally developed for fall prevention in nursing homes and has been associated with improvements in communication and participation in decision-making among clinical staff, as well as resident outcomes [51, 62, 63]. As with REP, CONNECT's design is suitable for rollout in various contexts and phases of implementation. For example, CONNECT may be an essential process for the creation of functional relationship networks and communication channels for learning, information exchange and problem solving for new clinical teams or programs in VAMCs (e.g., STRIDE), or as an effective team "booster" for existing groups that are incorporating new functions in clinical programs (e.g., Group PT, iHI-FIVES). CONNECT activities include group-based sessions designed to increase connections and information flow between providers and encourage them to seek out alternative explanations from others to make sense of new clinical data (cognitive diversity). Facilitator-led, group sessions use storytelling and role play to practice new behaviors. Additional sessions involve individuals mapping their relationships and communication patterns, discussing strategies for creative problem solving, and individual mentorship to sustain new interaction behaviors [51]. Function QUERI will evaluate the extent to which CONNECT affects team processes and characteristics, to facilitate team function (i.e., CFIR's inner setting) and in turn to affect implementation, patient, and service outcomes.

Function QUERI will adapt the CONNECT intervention for application in Function QUERI clinical contexts, where new clinical programs are composed of team members from multiple service units within a VA hospital. For example, participants targeted for CONNECT training vary across the three clinical program's delivery teams and their referring providers. CONNECT for the two larger, longer term projects will be informed by initial work of the single-site Group PT project, which will identify relevant components of CONNECT for improving team communication. Furthermore, CONNECT activities and didactic content will be modified to fit each clinical program. Role play will include scenarios related to issues surrounding each project's clinical problem, and the emphasis on CONNECT activities may differ. To illustrate, activities known as group and individual mapping are the likely focus of CONNECT team building for Group PT and iHI-FIVES because team members of these clinical programs work in different locations (i.e., service units) with limited opportunities for frequent interaction and thus require support for improving communications about appropriate referrals, administrative logistics, and communicating patients' clinical status. CONNECT training for STRIDE and iHIFIVES will be conducted prior to launch of clinical programs across multiple sites.

\section{Study design}

The Function QUERI's program goals are to assess (1) the effectiveness of the clinical programs and (2) the impact of CONNECT and team characteristics on clinical program implementation. The remainder of this paper focuses on the design of our evaluation of teams and CONNECT. Details on evaluations of clinical program effectiveness (i.e., patient outcomes) are available 
at clinicaltrials.gov (STRIDE no. NCT03300336 and iHIFIVES no. NCT03474380).

\section{Project 1: Group PT}

As a 1-year quality improvement project at a single site, the study design for Group PT is different than that of our multi-site implementation projects. Because the Durham VA Health Care System's Physical Medicine and Rehabilitation Service had already initiated implementation of Group PT for Veterans with knee OA, Function QUERI's role is to evaluate the program's successes, challenges, and outcomes to inform programmatic adaptations in a rapid timeframe, akin to a PlanDo-Study-Act cycle [64-66]. Function QUERI will also adapt and provide CONNECT Group-to-Group relationship mapping training to the team delivering Group PT, specifically tailored to address our operational partner's goals (Physical Medicine and Rehabilitation at the Durham VA Health Care System) to improve connections with providers from other service units and enhance communication about referrals and scheduling logistics. Using a mixed method design, we will continuously evaluate the Group PT program and identify influences of CONNECT on program outcomes, using quantitative and qualitative data reported quarterly to inform any refinements for the next 3-month implementation cycle. Importantly, implementation processes and evaluation from Group PT will be used to inform adjustments of CONNECT for our implementation of STRIDE and iHI-FIVES at multiple participating VAMCs.

\section{Projects 2 and 3: STRIDE and iHI-FIVES}

Clinical program implementation and testing of the CONNECT intervention for the STRIDE and iHI-FIVES implementation projects use a hybrid type III effectivenessimplementation design because the implementation intervention (CONNECT) and clinical programs (STRIDE and iHI-FIVES) have solid evidence bases but could yield weaker outcomes in new or less controlled environments $[51,67,68]$. To evaluate the effect of the clinical programs on Veteran outcomes, both projects use a stepped-wedge cluster randomized trial (CRT) design, which is ideal when the benefits of clinical programs are known but it may be logistically implausible to roll out the intervention simultaneously to all participating sites [69].

STRIDE and iHI-FIVES will each recruit eight unique participating sites for implementation and evaluation. Each project's implementation will occur in two stratified blocks (four VAMCs per block) with two waves per block (two VAMCs per wave) (Fig. 2). We will use two waves to minimize risk of site attrition based on long waits between enrollment and assigned implementation start date. Within blocks, each wave consisting of two VAMCs is randomized to a time period for implementation rollout (e.g., period 2 or 3 for sites in block 1 in Fig. 2). The length of the time periods may vary between projects (e.g., 3 or 6 months). Then, within each wave, each VAMC will be randomized to receive implementation consisting of either REP (standalone) or REP + CONNECT, with randomization assigned by a random number generated and conducted by study statisticians. Within the stepped-wedge design, there will be six time periods per VAMC site that are differentially split between pre-implementation (control) and post-implementation (treatment) periods depending on the wave and block of a site (see Fig. 2).

\section{Participating sites}

With assistance from our VA operation partners and marketing clinical programs through VAMC clinical conferences and national meetings, we will recruit sites on a volunteer basis. We will assess eligibility of sites to determine if they meet project-specific criteria that includes adequate sample size for evaluation. Specifically, STRIDE sites must have a minimum inpatient average daily census of 20 general medicine patients per day and iHI-FIVES sites must commit to conducting two rounds of iHI-FIVES training sessions every 6 months.

\section{Data: measurement and sources}

Evaluation of team and CONNECT impacts on implementation will employ a mixed methods design. Guided by our nested model of team function and performance in implementation, the implementation core will develop and collect common measures from primary and secondary data sources to evaluate team processes and characteristics, program characteristics, environmental context, and implementation outcomes. The data used to evaluate team and CONNECT impacts on clinical program implementation will be obtained from several sources, including provider/staff surveys and interviews, patient surveys and interviews, patient electronic medical record abstraction, and VA administrative data for patient encounters and VAMC performance measures. Since all projects' clinical programs utilize staff from existing care teams, inpatient wards, and service lines, Function QUERI will assess team characteristics and function before and after CONNECT training and program implementation. Sample measures and associated data sources are displayed in Table 2.

Team characteristics and processes will be primarily assessed using the Team Development Measure (TDM৫), a 31-item questionnaire, which characterizes teams' stage of development and the degree to which groups have the characteristics of highly effective teamwork in place [70, 71]. The TDM $\odot$ is ideally suited for Function QUERI's evaluation of teams because it has been tested in a variety of healthcare settings and maintains psychometric strength 


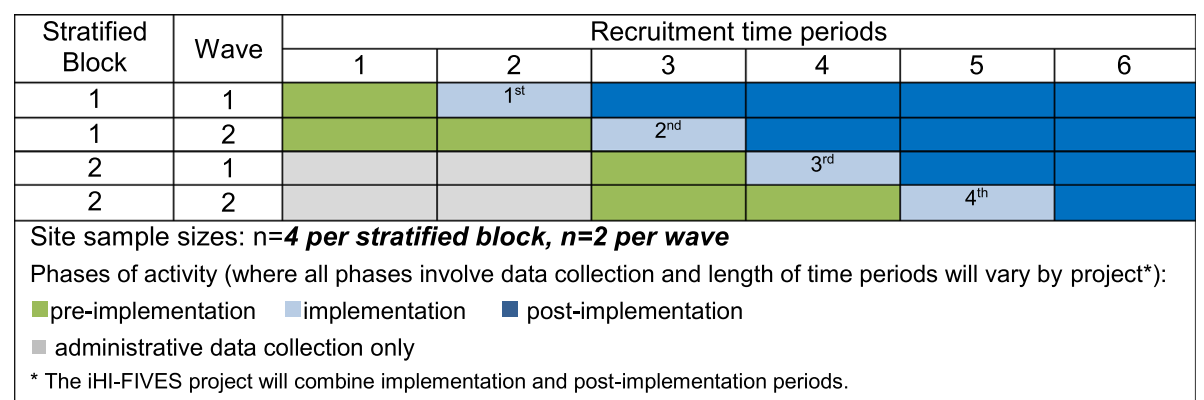

Fig. 2 Stepped-wedge design for the eight participating sites for STRIDE and iHI-FIVES implementation projects. Site sample sizes: $n=4$ per stratified block, $n=2$ per wave. Phases of activity (where all phases involve data collection and length of time periods will vary by project*): $\mathbf{m}$ pre-implementation, -implementation, - post-implementation,and - administrative data collection only. *The iHI-FIVES project will combine implementation and post-implementation periods

when applied to a range of group membership sizes. Items from the TDM $\odot$ also cluster to reflect the four key dimensions of team function: communication, role clarity, cohesion, and goal and means clarity [70]. This will enable the implementation core to (1) assess baseline and postimplementation changes in dimensions of team function, (2) identify variations in team strengths and weaknesses within and across clinical programs at participating sites, and (3) assess the dimensionality (e.g., one summative measure of team function or multiple measures of team function) and predictive power of team function on implementation and program outcomes to inform future implementation efforts.

The implementation core will supplement the TDM॰ with additional survey and interview questions identified from the literature on healthcare teams [72]. These additional items describe other important features of teams, including size, composition, and the degree to which team membership spans boundaries (e.g., clinical, professional). We will also describe team communication channels (internal, external), decision-making, and establishment of routines.

Clinical program characteristics include the components and processes that each site chooses for program delivery. Each site for STRIDE and iHI-FIVES will be provided with clinical program implementation packages that outline both the core and optional elements of each program. We will track how each site decides to structure their program and also assess other important elements associated with delivering the program such as task complexity and uncertainty, and dependence on other teams or clinical units within the organization.

Environmental context is an important consideration in our evaluation. Clinical programs and their teams operate within the broader context of local VAMCs that vary by facility complexity, organizational climate, presence of policies and practices to support innovative practices, and historical performance. These factors may work individually or in combination to support or challenge a team's ability to accomplish intended goals.

Implementation outcomes are the intermediate result of deliberate action in implementing new practices/services [73]. They serve as indicators of implementation processes that are the pre-condition for attainment of intended clinical and system-level change (i.e., program outcomes such as reductions in admission to nursing homes). This distinction is important, as it provides more specificity of the mechanisms underlying implementation successes or failures [73]. Given the overall goals of Function QUERI and the goals of our operational partners, we will focus on three main types of implementation outcomes: penetration, fidelity, and cost. Penetration of clinical programs is generally defined as proportion of eligible patients and/or caregivers who received clinical program services (e.g., referrals to iHIFIVES). Fidelity will be assessed via measures that describe patient/caregiver engagement (e.g., patient attendance for Group PT, caregivers' attendance for iHIFIVES), dose, and adherence to the protocol (e.g., STRIDE participants with at least one supervised walk). To assess budget impacts, we will assess costs related to program implementation and program delivery at each site, as well as patient-level resource utilization.

\section{Analytic approach}

Function QUERI's evaluation of implementation will focus on examining the impact of teams and the CONNECT implementation strategy, within and across projects. We will use a quantitatively driven simultaneous design (QUAN + qual) in which quantitative data constitute the core component and are collected in parallel with qualitative data [74, 75]. These two methods will be used to answer related questions, in that quantitative data will be used to evaluate implementation effectiveness and qualitative data to understand how implementation processes (including team processes) and environmental context related to implementation outcomes. Data integration will 
Table 2 Function QUERI measures and data sources

\begin{tabular}{|c|c|c|c|c|c|}
\hline \multirow[t]{2}{*}{ Data element } & \multicolumn{4}{|c|}{ Data sources } & \multirow[t]{2}{*}{ Projects } \\
\hline & VA admin & Survey & Interview & Field notes & \\
\hline \multicolumn{6}{|l|}{ Team characteristics } \\
\hline Team size: number of members of team for clinical program delivery & & & $x$ & & $1,2,3$ \\
\hline $\begin{array}{l}\text { Team composition: diversity of members within team to accomplish } \\
\text { tasks (e.g., expertise and skill set) and boundary spanning among team } \\
\text { memberships }\end{array}$ & & $x$ & $x$ & & $1,2,3$ \\
\hline $\begin{array}{l}\text { Role clarity: extent to which roles among team members are clearly } \\
\text { defined }\end{array}$ & & $x$ & $x$ & & $1,2,3$ \\
\hline $\begin{array}{l}\text { Cohesion: commitment in working as a collective unit to accomplish } \\
\text { the work of the team }\end{array}$ & & $x$ & $x$ & & $1,2,3$ \\
\hline \multicolumn{6}{|l|}{ Team processes } \\
\hline $\begin{array}{l}\text { Communication: open communication and participation in handling } \\
\text { conflict and solving problems as a collective unit }\end{array}$ & & $x$ & $x$ & & $1,2,3$ \\
\hline $\begin{array}{l}\text { Communication structure/channels: standardization and centralization } \\
\text { of conveying key information within team and externally }\end{array}$ & & & $x$ & & $1,2,3$ \\
\hline $\begin{array}{l}\text { Goal and means clarity: collective understanding of the work of the } \\
\text { team and its goals, and agreement on how their goals are reached }\end{array}$ & & $x$ & $x$ & & $1,2,3$ \\
\hline $\begin{array}{l}\text { Decision-making: manner in which information is exchanged and } \\
\text { decisions are made within teams (e.g., member involvement, } \\
\text { techniques of decision-making) }\end{array}$ & & $x$ & $x$ & & $1,2,3$ \\
\hline $\begin{array}{l}\text { Task interdependence: degree of dependence of tasks between } \backslash \\
\text { members within a team (team- and individual-level measures) }\end{array}$ & & & $x$ & & $1,2,3$ \\
\hline $\begin{array}{l}\text { Satisfaction/experience: employee satisfaction with the outcomes of } \\
\text { the team's work, to date. }\end{array}$ & & $x$ & $x$ & & $1,2,3$ \\
\hline \multicolumn{6}{|l|}{ Clinical program/task characteristics—Group PT, STRIDE, and HI-FIVES } \\
\hline $\begin{array}{l}\text { Task uncertainty: predictability in the work processes; presence of } \\
\text { standardized processes and protocols for different clinical scenarios }\end{array}$ & & & $x$ & & $1,2,3$ \\
\hline $\begin{array}{l}\text { Program interdependence: degree of dependence of tasks on other } \\
\text { clinical units }\end{array}$ & & $x$ & $x$ & & $1,2,3$ \\
\hline $\begin{array}{l}\text { Task interdependence: degree of dependence of tasks between team } \\
\text { members }\end{array}$ & & $x$ & $x$ & & $1,2,3$ \\
\hline \multicolumn{6}{|l|}{ Environmental context } \\
\hline $\begin{array}{l}\text { Facility complexity: operational complexity of VAMC (e.g., patients } \\
\text { served, case-mix, and intensive care unit level) }\end{array}$ & VA Planning & & & & $1,2,3$ \\
\hline $\begin{array}{l}\text { Climate: share perception on the degree to which clinical program is } \\
\text { supported, rewarded, and expected within VAMC }\end{array}$ & & $x$ & $x$ & & $1,2,3$ \\
\hline Leadership, clinical champion & & & $x$ & & \\
\hline $\begin{array}{l}\text { Policies, practices, and procedures: organizational effort to support } \\
\text { innovative practices within VAMC (e.g., performance monitoring) }\end{array}$ & & & $x$ & & $1,2,3$ \\
\hline $\begin{array}{l}\text { Historical performance: prior innovation history, organizational } \\
\text { performance on related clinical metrics }\end{array}$ & SAIL, IPEC, AES & & $x$ & & $1,2,3$ \\
\hline \multicolumn{6}{|l|}{ Implementation outcomes } \\
\hline $\begin{array}{l}\text { Penetration: reach (referrals, initiation rate), integration of program } \\
\text { within VAMC's relevant clinical units }\end{array}$ & $\begin{array}{l}\text { Chart review } \\
\text { VA visits, claims }\end{array}$ & $x$ & $x$ & $x$ & $1,2,3$ \\
\hline $\begin{array}{l}\text { Fidelity: degree to which program is implemented } \\
\text { - Adherence to protocol } \\
\text { - Participant engagement }\end{array}$ & $\begin{array}{l}\text { Project records } \\
\text { Chart review } \\
\text { VA visits, claims }\end{array}$ & & $x$ & $x$ & $1,2,3$ \\
\hline $\begin{array}{l}\text { Cost } \\
\cdot \text { - Total implementation cost }\end{array}$ & $\begin{array}{l}\text { Project records } \\
\text { VHA salary }\end{array}$ & & $x$ & $x$ & 2,3 \\
\hline
\end{tabular}

- Total program delivery cost

- Resource utilization costs 
Table 2 Function QUERI measures and data sources (Continued)

\begin{tabular}{|c|c|c|c|c|c|}
\hline \multirow[t]{2}{*}{ Data element } & \multicolumn{4}{|c|}{ Data sources } & \multirow[t]{2}{*}{ Projects } \\
\hline & VA admin & Survey & Interview & Field notes & \\
\hline \multicolumn{6}{|l|}{$\begin{array}{l}\text { Clinical and service-level outcomes (sample measures obtained at the } \\
\text { patient-level) }\end{array}$} \\
\hline $\begin{array}{l}\text { Program service use: referrals, scheduled appointments, participation, } \\
\text { attendance, distance walked, }\end{array}$ & $\begin{array}{l}\text { Chart review } \\
\text { VA visits, claims }\end{array}$ & & & & \\
\hline $\begin{array}{l}\text { Function: function and disability instrument, WOMAC pain and } \\
\text { physical function scale, Zarit subjective burden scale, Center for } \\
\text { Epidemiology Studies Depression Scale }\end{array}$ & Chart review & $x$ & & & $1,2,3$ \\
\hline $\begin{array}{l}\text { Independence: days in home/community, discharge to nursing home, } \\
\text { skilled nursing, wait times }\end{array}$ & & & & & 2,3 \\
\hline Quality of life: health-related quality of life & & $x$ & & & \\
\hline $\begin{array}{l}\text { Resource utilization: outpatient visits, hospitalization, ER, discharge to } \\
\text { nursing home, skilled nursing, wait times }\end{array}$ & $\begin{array}{l}\text { Chart review } \\
\text { VA visits, claims }\end{array}$ & & & & $1,2,3$ \\
\hline Patient satisfaction: CAHPS survey items on satisfaction & & $x$ & $x$ & & $1,2,3$ \\
\hline
\end{tabular}

involve embedding qualitative process data within the quantitative outcomes data (for example, in a matrix format in which program sites are arranged from high to low penetration) to evaluate the relationship between implementation outcomes and process for both implementation strategies (e.g., REP alone vs. REP + CONNECT).

To assess the relationship between teams and implementation outcomes, we will examine how fidelity and penetration outcomes change over time by team measures. For example, prior work [70] has demonstrated that items from the TDM $\odot$ reflect team communication, role clarity, cohesion, and goal and means clarity. Survey items from the larger team survey may cluster to reflect other dimensions of team function, which will enable Function QUERI to examine predictive power of team characteristics on implementation and program outcomes. Pre- and post-implementation survey administration will also enable assessment of temporal changes in team function. Specifically, prior experience suggests that baseline team structure and communication effectiveness modifies the impact of CONNECT, with highly functioning or dysfunctional teams receiving less benefit. Thus, by capturing baseline team measures, we will be able to assess for this effect. Furthermore, if we find that the implementation strategy REP + CONNECT improves implementation outcomes compared to REP alone, we will examine whether team measures mediate or moderate this effect following methods of MacKinnon [76] and Kraemer [76, 77].

We anticipate that sites randomized to implementation via REP + CONNECT will achieve higher rates of implementation effectiveness (e.g., higher penetration, fidelity) than sites receiving REP alone. To evaluate the impact of CONNECT on clinical program implementation, penetration, fidelity, and cost outcomes will be assessed only in the post-implementation period and primary analyses will be conducted on implementation outcomes observed in the first post-implementation period to avoid potential confounding with time since implementation. We will use appropriate logistic or linear mixed regression models [78-81], where the main predictor of interest will be REP vs. REP + CONNECT adjusting for clustering of VAMC with either a random effect or by conditioning.

Organization-specific context and processes are likely to affect both implementation and program outcomes. Our quantitative findings will be complemented by additional analyses of context sensitivity and qualitative data from semi-structured interviews with key informants at participating sites. Responses will be coded and analyzed at individual and team levels, using both a priori labels of facility context, team processes and implementation outcomes, and data-derived labels to develop site-level case memo summaries of contextual factors and team processes. From this coded data, we will identify and visually display emergent themes in a matrix, with columns reflecting implementation outcomes (i.e., fidelity and penetration) arranged from high to low, to illustrate patterns in contextual factors and team processes according to implementation outcomes. For example, we will develop a matrix to compare reports of implementation processes and outcomes between REP alone and REP + CONNECT sites. The rows of the matrix will reflect a priori implementation measures, and the columns will reflect whether responses are from REP or REP + CONNECT sites.

Utilizing a similar approach across projects, we will perform budget impact analysis for STRIDE and iHI-FIVES multi-site projects to frame affordability to the VHA [82]. Depending on the evaluation results of STRIDE and iHIFIVES implementation projects, budget impacts will particularly focus on comparing total costs by the implementation strategy of REP alone vs. REP + CONNECT. 
Since CONNECT is expected to be more time-intensive and expensive than REP, it is critical to consider the relative gains (if any) to both team function and patient outcomes from adding CONNECT training to REP. For these projects, we will also consider variability in budgetary impact by site (e.g., costs may differ by low versus high penetration sites or by team composition). We will calculate the budget impacts of the clinical programs and compare them to each program's value. The value will be defined in light of all of the evaluation evidence. For example, the value may be framed as total budget impact per unit gain in patient function or as total budget impact compared to the clinical team's narrative on how a program benefited patients. We will also consider framing budgetary impact against different domains, such as total costs by site or costs per Veteran participant. The Function QUERI investigators leading the clinical programs will work with the implementation core and VA operational partners to develop appropriate comparisons.

\section{Discussion}

\section{Limitations and challenges}

The Function QUERI set an ambitious and important agenda to explore ways to effectively disseminate and implement innovative evidence-based clinical programs across the VA health system. There is a significant amount of work that presents challenges and opportunities. First, conducting the implementation and evaluation, with an a prior stepped-wedge design in ever changing real-world settings, forces Function QUERI to delicately balance considerations of study design and voluntary participation in implementing clinical programs. To this end, our use of REP to work with sites in a systematic and standardized way is a great strength in facilitating local adaptations to optimize implementation. Second, our selection of volunteer sites may limit heterogeneity in our sample. However, there is a great deal to learn about implementation processes and adaptations in real-world settings to inform continuous improvement and to the likelihood of effective uptake and sustainability of valuable clinical intervention. Third, our measurement approach involves significant effort in primary data collection of patient and provider surveys, interviews, and extraction of secondary administrative/clinical data with attention to common measures across three contextually disparate clinical contexts. The challenges of data collection and management may be outweighed by the opportunity to generate a broader, nuanced understanding of implementation in hospital settings and to facilitating effective interdisciplinary team function across VA settings.

\section{Summary}

Function QUERI will achieve an immediate impact on the VHA by providing access to evidence-based clinical services for a large group of vulnerable Veterans at risk for functional decline and loss of independence. A longterm impact will be to enhance VA's capacity for clinical innovation through development and testing of an implementation intervention (CONNECT) to enhance uptake of evidence-based programs in interdisciplinary teams. To this end, the Function QUERI program will specify dimensions of team characteristics and function that enhance capacity for clinical innovation and uptake of evidence-based programs. Synthesizing findings within and across projects, we will translate implementation findings to identify the contextual factors and components from CONNECT that improve team processes and function to optimize future wide-scale implementation of VA clinical programs.

\section{Additional file}

Additional file 1: Function QUERI implementation activities, by phase of REP (indicated by green arrows) and highlighting application of CONNECT (red arrows) for each project. (DOCX $222 \mathrm{~kb}$ )

\section{Abbreviations}

CFIR: Consolidated Framework for Implementation Research; Group PT: Group physical therapy for knee osteoarthritis; HI-FIVES: Helping invested family members improve veteran experiences study; iHI-FIVES: Implementation of helping invested family members improve veteran experiences study; IoC: Implementation of change; PT: Physical therapy; QUERI: Quality enhancement research initiative; REP: Replicating Effective Programs; STRIDE: Assisted early mobility for hospitalized older veterans; TDM ${ }^{\odot}$ : Team Development Measure; VA: Veterans administration; VAMC: Veterans Administration Medical Center; VHA: Veterans Health Administration

\section{Acknowledgements}

The authors thank Eugene Oddone, Henry Crevensten, Rebecca Bruening, Ashley Choate, Joshua D’Adolf, Kasey Decosimo, Katina Morris, Caitlin Sullivan, Anne Sales, Mark Bauer, Christopher Miller, members of the Function QUERI Advisory Board, and Veteran and Caregiver participants of the Function QUERI Veteran and Family Input Initiative group. All views expressed are those of the authors and do not reflect the official policy or views of the US Government, the Department of Veterans Affairs, Duke University, Indiana University, the University of North Carolina at Chapel Hill, or the University of California.

\section{Funding}

This study was funded by the Department of Veterans Affairs (VA) Quality Enhancement Research Initiative (QUE-16-170) and supported by the Center of Innovation for Health Services Research in Primary Care at the Durham VA Health Care System (CIN 13-410).

\section{Availability of data and materials}

The scope of this work is being done as quality improvement; the data will only be available from the authors upon request and approval by the authorizing officials.

\section{Authors' contributions}

All the authors are investigators on this funded program, and all contributed to the approved proposal. The original proposal was substantially longer than the journal's word limit, and much of the scope and text was reduced for this manuscript. W led the revision of the proposal into its current form. $\mathrm{KDA}, \mathrm{SNH}, \mathrm{CVH}$, and $\mathrm{W}$ are co-principal investigators. All other authors are co-investigators and the Function QUERI program coordinator. All authors contributed to the research design, critically reviewed, and approved the final manuscript. 


\section{Ethics approval and consent to participate}

This program was funded through the VA Quality Enhancement Research Initiative (QUERI) program. VA QUERI funds are operational funds in the Veterans Health Administration, and much of the work funded through QUERI is conducted as quality improvement. The Department of Veterans Affairs has specific guidance for the approval of work done as Ql, as outlined in VHA Handbook 1058.05. The authors provided supporting documentation that attest to meeting the requirements under this guidance, which is available from the authors upon request.

\section{Competing interests}

Courtney Van Houtven received payment for consultation for Truven Analytics. All other authors (VW, CVH, KDA, CC, NS, EM, CCE, HH, GL, TMD, $\mathrm{EP}, \mathrm{SNH})$ declare no competing interests.

\section{Publisher's Note}

Springer Nature remains neutral with regard to jurisdictional claims in published maps and institutional affiliations.

\begin{abstract}
Author details
${ }^{1}$ Health Services Research and Development Center of Innovation, Durham Veterans Affairs Health Care System, 508 Fulton St., Durham, NC 27705, USA. ${ }^{2}$ Department of Population Health Sciences, Duke University School of Medicine, Durham, NC, USA. ${ }^{3}$ Department of Medicine, Duke University School of Medicine, Durham, NC, USA. ${ }^{4}$ Department of Medicine and Thurston Arthritis Research Center, University of North Carolina at Chapel Hill, Chapel Hill, NC, USA. ${ }^{5}$ Department of Biostatistics and Bioinformatics, Duke University School of Medicine, Durham, NC, USA. ${ }^{6}$ Geriatric Research Education and Clinical Center, Durham VA Health Care System, Durham, NC, USA. ${ }^{7}$ Physical Medicine and Rehabilitation Service, Durham VA Health Care System, Durham, NC, USA. ${ }^{8}$ Health Services Research and Development Center for Health Information and Communication, Roudebush Veterans Affairs Medical Center, 1481 W. 10th St., HSRD 11H, Indianapolis, IN 46202, USA. ${ }^{9}$ Department of General Internal Medicine and Geriatrics, Indiana University School of Medicine, Indianapolis, IN, USA. ${ }^{10}$ Regenstrief Institute, Inc., Indianapolis, IN, USA. ${ }^{11}$ San Francisco VA Care System, 94121, 4150 Celement St., Box 111, San Francisco, CA, USA. ${ }^{12}$ Department of Medicine, University of California San Francisco, San Francisco, CA, USA.
\end{abstract}

Received: 8 December 2017 Accepted: 10 April 2018

Published online: 20 April 2018

\section{References}

1. Roethlisberger FJ, D WJ. Management and the worker. Cambridge: Harvard University Press; 1939.

2. Hasenfield Y. Human service organizations. Englewood Cliffs: Prentice-Hall; 1983.

3. Porter LW, Lawler EE III, Hackman JR. Behavior in organizations. New Yourk: McGraw-Hill; 1975.

4. Lanham HJ, Leykum LK, Taylor BS, McCannon CJ, Lindberg C, Lester RT. How complexity science can inform scale-up and spread in health care: understanding the role of self-organization in variation across local contexts. Soc Sci Med. 2013;93:194-202.

5. McDaniel RR Jr, Driebe DJ, Lanham HJ. Health care organizations as complex systems: new perspectives on design and management. Adv Health Care Manag. 2013;15:3-26.

6. Helfrich CD, Dolan ED, Finn SD, Rodriguez HP, Meredith LS, Rosland AM, Lempa M, Wakefield BJ, Joos S, Lawler LH, et al. Association of medical home team-based care functions and perceived improvements in patientcentered care at VHA primary care clinics. Healthc (Amst). 2014;2:238-44.

7. Gill TM, Allore HG, Gahbauer EA, Murphy TE. Change in disability after hospitalization or restricted activity in older persons. JAMA. 2010;304: 1919-28.

8. Murphy L, Schwartz TA, Helmick CG, Renner JB, Tudor G, Koch G, Dragomir A, Kalsbeek WD, Luta G, Jordan JM. Lifetime risk of symptomatic knee osteoarthritis. Arthritis Rheum. 2008;59:1207-13.

9. Lawrence RC, Felson DT, Helmick CG, Arnold LM, Choi H, Deyo RA, Gabriel S, Hirsch R, Hochberg MC, Hunder GG, et al. Estimates of the prevalence of arthritis and other rheumatic conditions in the United States: part II. Arthritis Rheum. 2008:58:26-35.
10. Johnson VL, Hunter DJ. The epidemiology of osteoarthritis. Best Pract Res Clin Rheumatol. 2014;28:5-15.

11. Hootman JM, Helmick CG, Brady TJ. A public health approach to addressing arthritis in older adults: the most common cause of disability. Am J Public Health. 2012;102:426-33.

12. Verbrugge $L M$, Juarez L. Arthritis disability and heart disease disability. Arthritis Care Res. 2008;59:1445-57.

13. Hawker GA. The challenge of pain for patients with OA. HSS J. 2012;8:42-4.

14. Guccione AA, Felson DT, Anderson JJ, Anthony JM, Zhang Y, Wilson PW, Kelly-Hayes M, Wolf PA, Kreger BE, Kannel WB. The effects of specific medical conditions on the functional limitations of elders in the Framingham Study. Am J Public Health. 1997;84:351-8.

15. Davis MA, Ettinger WH, Neuhaus JM, Mallon KP. Knee osteoarthritis and physical functioning: evidence from the NHANES I epidemiologic followup study. J Rheumatol. 1991:18:591-8.

16. Hochberg MC, Kasper J, Williamson JD, Skinner A, Fried LP. The contribution of osteoarthritis to disability: preliminary data from the Women's Health and Aging Study. J Rheumatol. 1995;22:16-8.

17. Bennell KL, Hinman RS, Metcalf BR, Buchbinder R, McConnell J, McColl G, Green S, Crossley KM. Efficacy of physiotherapy management of knee joint osteoarthritis: a randomised, double blind, placebo controlled trial. Ann Rheum Dis. 2005;64:906-12.

18. Deyle GD, Allison SC, Matekel RL, Ryder MG, Stang JM, Gohdes DD, Hutton JP, Henderson NE, Garber MB. Physical therapy treatment effectiveness for osteoarthritis of the knee: a randomized comparison of supervised clinical exercise and manual therapy procedures versus a home exercise program. Phys Ther. 2005:85:1301-17.

19. Deyle GD, Henderson NE, Matekel RL, Ryder MG, Garber MB, Allison SC. Effectiveness of manual physical therapy and exercise in osteoarthritis of the knee. A randomized, controlled trial. Ann Intern Med. 2000;132:173-81.

20. Fransen M, Crosbie J, Edmonds J. Physical therapy is effective for patients with osteoarthritis of the knee: a randomized controlled clinical trial. J Rheumatol. 2001;28:156-64.

21. Jamtvedt G, Dahm KT, Christie A, Moe RH, Haavardsholm E, Holm I, Hagen KB. Physical therapy interventions for patients with osteoarthritis of the knee: an overview of systematic reviews. Phys Ther. 2008;88:123-36.

22. Wang SY, Olson-Kellogg B, Shamliyan TA, Choi JY, Ramakrishnan R, Kane RL. Physical therapy interventions for knee pain secondary to osteoarthritis: a systematic review. Ann Intern Med. 2012;157:632-44.

23. Allen KD, Bosworth HB, Chatterjee R, Coffman CJ, Corsino L, Jeffreys AS, Oddone EZ, Stanwyck C, WSJ Y, Dolor RJ. Clinic variation in recruitment metrics, patient characteristics and treatment use in a randomized clinical trial of osteoarthritis management. BMC Musculoskelet Disord. 2014;15:413.

24. Allen KD, Bongiorni D, Bosworth HB, Coffman CJ, Datta SK, Edelman D, Hall $\mathrm{KS}$, Lindquist $\mathrm{JH}$, Oddone EZ, Hoenig $\mathrm{H}$. Group versus individual physical therapy for veterans with knee osteoarthritis: randomized clinical trial. Phys Ther. 2016:96:597-608.

25. Zisberg A, Shadmi E, Sinoff G, Gur-Yaish N, Srulovici E, Admi H. Low mobility during hospitalization and functional decline in older adults. J Am Geriatr Soc. 2011;59:266-73

26. Brown CJ, Redden DT, Flood KL, Allman RM. The underrecognized epidemic of low mobility during hospitalization of older adults. J Am Geriatr Soc. 2009:57:1660-5

27. Murphy EA. A key step for hospitalized elders. Arch Intern Med. 2011; 171:268-9.

28. Brown CJ, Foley KT, Lowman JD Jr, MacLennan PA, Razjouyan J, Najafi B, Locher J, Allman RM. Comparison of posthospitalization function and community mobility in hospital mobility program and usual care patients: a randomized clinical trial. JAMA Intern Med. 2016;176:921-7.

29. Fisher SR, Kuo YF, Graham JE, Ottenbacher KJ, Ostir GV. Early ambulation and length of stay in older adults hospitalized for acute illness. Arch Intern Med. 2010;170:1942-3.

30. Growdon ME, Shorr RI, Inouye SK. The tension between promoting mobility and preventing falls in the hospital. JAMA Intern Med. 2017;177:759-60.

31. Kalisch BJ, Lee S, Dabney BW. Outcomes of inpatient mobilization: a literature review. J Clin Nurs. 2014;23:1486-501.

32. Liu B, Moore JE, Almaawiy U, Chan WH, Khan S, Ewusie J, Hamid JS, Straus $\mathrm{SE}$, Collaboration MO. Outcomes of Mobilisation of Vulnerable Elders in Ontario (MOVE ON): a multisite interrupted time series evaluation of an implementation intervention to increase patient mobilisation. Age Ageing. 2018:47:112-9. 
33. Ostir GV, Berges IM, Kuo YF, Goodwin JS, Fisher SR, Guralnik JM. Mobility activity and its value as a prognostic indicator of survival in hospitalized older adults. J Am Geriatr Soc. 2013;61:551-7.

34. Pashikanti L, Von Ah D. Impact of early mobilization protocol on the medical-surgical inpatient population: an integrated review of literature. Clin Nurse Spec. 2012;26:87-94

35. Mundy LM. Early mobilization of patients hospitalized with communityacquired pneumonia. Chest. 2003;124:883-9.

36. Hastings SN, Sloane R, Morey MC, Pavon JM, Hoenig H. Assisted early mobility for hospitalized older veterans: preliminary data from the STRIDE program. J Am Geriatr Soc. 2014;62:2180-4.

37. Van Houtven $\mathrm{CH}$, Norton EC. Informal care and health care use of older adults. J Health Econ. 2004;23:1159-80.

38. Van Houtven $\mathrm{CH}$, Oddone EZ, Weinberger M. Informal and formal care infrastructure and perceived need for caregiver training for frail US veterans referred to home and community-based services. Chronic IIIn. 2010;6:57-66.

39. Wray LO, Shulan MD, Toseland RW, Freeman KE, Vasquez BE, Gao J. The effect of telephone support groups on costs of care for veterans with dementia. Gerontologist. 2010;50:623-31.

40. Nichols LO, Martindale-Adams J, Burns R, Graney MJ, Zuber J. Translation of a dementia caregiver support program in a health care system--REACH VA. Arch Intern Med. 2011;171:353-9.

41. Mittelman MS, Ferris SH, Shulman E, Steinberg G, Ambinder A, Mackell JA, Cohen J. A comprehensive support program: effect on depression in spouse-caregivers of AD patients. Gerontologist. 1995;35:792-802.

42. Mittelman MS, Haley WE, Clay OJ, Roth DL. Improving caregiver well-being delays nursing home placement of patients with Alzheimer disease. Neurology. 2006;67:1592-9.

43. Belle SH, Burgio L, Burns R, Coon D, Czaja SJ, Gallagher-Thompson D, Gitlin LN, Klinger J, Koepke KM, Lee CC, et al. Enhancing the quality of life of dementia caregivers from different ethnic or racial groups: a randomized, controlled trial. Ann Intern Med. 2006;145:727-38.

44. Gitlin LN, Hauck WW, Winter L, Dennis MP, Schulz R. Effect of an in-home occupational and physical therapy intervention on reducing mortality in functionally vulnerable older people: preliminary findings. J Am Geriatr Soc. 2006:54:950-5

45. Van Houtven $\mathrm{CH}$, Oddone EZ, Hastings SN, Hendrix C, Olsen MK, Neelon B, Lindquist J, Weidenbacher H, Boles J, Chapman J, Weinberger M. Helping invested families improve veterans' experiences (HI-FIVES) study: study design and methodology. Contemp Clin Trials. 2014;38:260-9.

46. Grol R, Wensing M. Effective implementation: a model. In: Grol R, Wensing $M$, Eccles $M$, editors. Improving patient care: the implementation of change in clinical practice. Edinburgh: Elsevier; 2005. p. 41-57.

47. Damschroder LAD, Keith R, Kirsh S, Alexander J, Lowery J. Fostering implementation of health services research findings into practice: a consolidated work framework for advancing implementation science. Implement Sci. 2009;4:50

48. Plsek P, Greenhalgh T. The challenge of complexity in health care. Br Med J. 2001;323:625-8.

49. Kilbourne AM, Neumann MS, Pincus HA, Bauer MS, Stall R. Implementing evidence-based interventions in health care: application of the replicating effective programs framework. Implement Sci. 2007;2:42.

50. Anderson RA, Corazzini K, Porter K, Daily K, McDaniel RR Jr, ColonEmeric C. CONNECT for quality: protocol of a cluster randomized controlled trial to improve fall prevention in nursing homes. Implement Sci. 2012;7:11.

51. Colon-Emeric CS, McConnell E, Pinheiro SO, Corazzini K, Porter K, Earp KM, Landerman L, Beales J, Lipscomb J, Hancock K, Anderson RA. CONNECT for better fall prevention in nursing homes: results from a pilot intervention study. J Am Geriatr Soc. 2013;61:2150-9.

52. Replicating effective programs. https://www.cdc.gov/hiv/research/ interventionresearch/rep/index.html. Accessed 10 Nov 2017.

53. Kilbourne AM, Abraham KM, Goodrich DE, Bowersox NW, Almirall D, Lai Z, Nord KM. Cluster randomized adaptive implementation trial comparing a standard versus enhanced implementation intervention to improve uptake of an effective re-engagement program for patients with serious mental illness. Implement Sci. 2013;8:136

54. Kind AJ, Brenny-Fitzpatrick M, Leahy-Gross K, Mirr J, Chapman E, Frey B, Houlahan B. Harnessing protocolized adaptation in dissemination: successful implementation and sustainment of the veterans affairs coordinated- transitional care program in a non-veterans affairs hospital. J Am Geriatr Soc. 2016:64:409-16.

55. Bauer MS, Damschroder L, Hagedorn H, Smith J, Kilbourne AM. An introduction to implementation science for the non-specialist. BMC Psychol. 2015;3:32.

56. Bandura A. Self-efficacy: toward a unifying theory of behavioral change. Psychol Rev. 1977:84:191-215.

57. Bandura A, Adams NE, Beyer J. Cognitive processes mediating behavioral change. J Pers Soc Psychol. 1977;35:125-39.

58. Palincsar AS. Social constructivist perspectives on teaching and learning Annu Rev Psychol. 1998:49:345-75.

59. Colon-Emeric CS, Pinheiro SO, Anderson RA, Porter K, McConnell E, Corazzin K, Hancock K, Lipscomb J, Beales J, Simpson KM. Connecting the learners: improving uptake of a nursing home educational program by focusing on staff interactions. Gerontologist. 2014;54:446-59.

60. Bandura A. Social learning theory. New York: General Learning Press; 1977.

61. McConnell ES, Lekan D, Hebert C, Leatherwood L. Academic-practice partnerships to promote evidence-based practice in long-term care: oral hygiene care practices as an exemplar. Nurs Outlook. 2007:55:95-105.

62. Anderson RA, Toles MP, Corazzini K, McDaniel RR, Colon-Emeric C. Local interaction strategies and capacity for better care in nursing homes: a multiple case study. BMC Health Serv Res. 2014;14:244.

63. Colon-Emeric CS, Corazzini K, McConnell ES, Pan W, Toles M, Hall R, Cary MP Jr, Batchelor-Murphy M, Yap T, Anderson AL, et al. Effect of promoting highquality staff interactions on fall prevention in nursing homes: a clusterrandomized trial. JAMA Intern Med. 2017;177:1634-41.

64. Science of improvement: how to improve. http://www.ihi.org/resources/ Pages/Howtolmprove/default.aspx. Accessed 10 Nov 2017.

65. Deming WE. The new economics for industry, government, and education. Boston: MIT Press; 1993.

66. Berwick DM. Developing and testing changes in delivery of care. Ann Intern Med. 1998:128:651-6.

67. Curran GM, Bauer M, Mittman B, Pyne JM, Stetler C. Effectivenessimplementation hybrid designs: combining elements of clinical effectiveness and implementation research to enhance public health impact. Med Care. 2012;50:217-26.

68. Kilbourne AM, Goodrich DE, Nord KM, Van Poppelen C, Kyle J, Bauer MS, Waxmonsky JA, Lai Z, Kim HM, Eisenberg D, Thomas MR. Long-term clinical outcomes from a randomized controlled trial of two implementation strategies to promote collaborative care attendance in community practices. Admin Pol Ment Health. 2015;42:642-53.

69. Hemming K, Lilford R, Girling AJ. Stepped-wedge cluster randomised controlled trials: a generic framework including parallel and multiple-level designs. Stat Med. 2015:34:181-96.

70. Stock R, Mahoney E, Carney PA. Measuring team development in clinical care settings. Fam Med. 2013;45:691-700.

71. Salem-Schatz S OD, Mittman B: Guide to the team development measure. Center for implementation practice and research support; 2010

72. Valentine MA, Nembhard IM, Edmondson AC. Measuring teamwork in health care settings: a review of survey instruments. Med Care. 2015; 53:e16-30.

73. Proctor E, Silmere H, Raghavan R, Hovmand P, Aarons G, Bunger A, Griffey R, Hensley M. Outcomes for implementation research: conceptual distinctions, measurement challenges, and research agenda. Admin Pol Ment Health. 2011;38:65-76.

74. Morse JM, Niehaus L. Mixed method design : principles and procedures. Walnut Creek: Left Coast Press; 2009.

75. Palinkas LA, Horwitz SM, Green CA, Wisdom JP, Duan N, Hoagwood K. Purposeful Sampling for Qualitative Data Collection and Analysis in Mixed Method Implementation Research. Adm Policy Ment Health. 2015;42(5):533-44

76. Mackinnon DP, Fairchild AJ, Fritz MS. Mediation analysis. Annu Rev Psychol. 2007;58:593-614.

77. Kraemer HC, Wilson GT, Fairburn CG, Agras WS. Mediators and moderators of treatment effects in randomized clinical trials. Arch Gen Psychiatry. 2002; 59:877-83.

78. Localio AR, Berlin JA, Ten Have TR, Kimmel SE. Adjustments for center in multicenter studies: an overview. Ann Intern Med. 2001:135:112-23.

79. Kahan BC. Accounting for centre-effects in multicentre trials with a binary outcome--when, why, and how? BMC Med Res Methodol. 2014:14:20.

80. Hedeker RGR. Longitudinal data analysis. Hoboken: Wiley; 2006. 
81. Verbeke GMG. Linear mixed models for longitudinal analysis. New York: Springer-Verlag; 2000.

82. Sullivan SD, Mauskopf JA, Augustovski F, Jaime Caro J, Lee KM, Minchin M, Orlewska E, Penna P, Rodriguez Barrios JM, Shau WY. Budget impact analysis-principles of good practice: report of the ISPOR 2012 Budget Impact Analysis Good Practice II Task Force. Value Health. 2014;17:5-14.

Ready to submit your research? Choose BMC and benefit from:

- fast, convenient online submission

- thorough peer review by experienced researchers in your field

- rapid publication on acceptance

- support for research data, including large and complex data types

- gold Open Access which fosters wider collaboration and increased citations

- maximum visibility for your research: over $100 \mathrm{M}$ website views per year 